\title{
In Search of Individual and Organizational Fairness in Policing
}

\author{
Steven Chase, Director of People, Thames Valley Police
}

\begin{abstract}
This paper considers individual and organizational fairness in policing and explores the opportunities to promote a culture of learning, drawing on organizational justice research literature, together with practice reflection. An attempt is made to synthesize the two into a working model of fairness in organizations. The paper examines how leadership style might influence such an ambition and how adopting a culture of learning and fairness might produce more organizationally just outcomes in Human Resources policy and practice, such as misconduct and performance procedures. The paper concludes that further research through the lens of 'organizational story telling' would add a richness to the research to date much of which has tended to be quantitative in nature.
\end{abstract}

Key words: policing, leadership, organizational justice, fairness, learning, culture

\section{Introduction}

The aim of this paper is to provide a scholarly-practice consideration of how organizations might begin to construct pathways to promote a culture of learning in the context of the increasingly important and politically sensitive dimension of organizational fairness and justice. The paper is situated within UK police practice and draws, critically, on extant research and the experience of the author from 20 years in Human Resource Management within a UK police force. The paper makes no claim to be an empirically based 'answer' to the problem of fairness and justice within organizations. Rather it provides a discussion platform from which organizations might seek to develop and sustain their own policies and practice.

A number of high profile, serious issues - some historic like the tragic events at the Hillsborough football ground in Sheffield in 1989, some more recent events such as failings in child sexual exploitation investigations and misconduct by a small number of individuals - have led to reputational damage. They have also led to criticism of the police service in general and of some forces and individuals in particular. Readers should be clear from the outset that this is far from a clean landscape within a straight forward context. Politicians, the media, Her Majesty's Inspectorate of Constabulary (now Her Majesty's Inspectorate of Constabulary and Fire and Rescue Services), the Independent Police Complaints Commission (now The Independent Office for Police Conduct), as well as police forces and the criminal justice system more broadly, also tread this ground. In the interests of public confidence and policing legitimacy, it is hard to imagine a more important theatre to stage Human Resources interventions which promote a just culture within the policing family.

As a result, there has been a growing interest in concepts of procedural justice and their association with improved public confidence, trust in policing and policing legitimacy (Hough et al., 2010). Concepts of organizational justice and fairness have received far less attention 
in policing organizations. This article attempts to take a small step in shining a light on these concepts and postulates a relationship between leadership style and organizational justice, which in turn feeds procedural justice and policing legitimacy.

Despite an extensive academic literature around organizational justice, fairness, and blame - see the academic research context section of this paper for a brief insight - and some attempts (Syed, 2015) to bring research into practice, the practical world of people management remains relatively underexposed to these ideas as elements of leadership style and their links to organizational learning and organizational fairness. Whilst it has been argued that leadership is an essential organizational success factor (Alvesson et al., 2017) there is often little consensus about what constitutes good leadership, policing being a good example of where this debate flourishes. At best, it is a 'contested concept'.

How employees perceive concepts of justice and fairness within organizations are increasingly seen as barometers of organizational climate and organizational culture (Schneider et al., 2013). In the language of 'employer of choice' they have become integral elements of employee attraction and retention. In the everyday parlance of our workforces, the words 'justice' and 'fairness' are used interchangeably and likely to feature in the people strategies, policies, and procedures of many organizations. Increasingly, leaders strive to position themselves in a supportive, coaching role and the Human Resources professional seeks to position themselves as genuine business partners, driving business change through people centric, fair process activity.

For this writer at least, in trying to illustrate the explicit relationships between leadership, fairness, organizational justice and organizational learning, there are four key pillars of debate. First, how do we understand concepts of fairness in organizations? Second, how do we foster a leadership style and an organizational climate where we create opportunities for learning from mistakes, avoiding the rush to tag such mistakes as blameworthy events? Third, how do we turn near misses - that is, events that might have happened, but did not for reasons of good fortune or positive interventions - into organizational learning opportunities? Fourth, how do we know our organizational climate is moving towards a fairer and more just working environment?

In an attempt to address these four areas of debate, this paper aims to examine concepts of justice and fairness in an organizational context, discuss some of the academic literature around organizational justice and fairness and seek to illustrate the relationship between organizational fairness and organizational learning in pursuit of a more just culture. The narrative will then proceed to a model of organizational justice and a shorthand mnemonic for organizational fairness, before looking at how they might be used to gain some sense of fairness in practice if the models are applied to leadership interventions and to Human Resources policy and practice. The concepts apply across a wide range of people management activity, including recruitment, progression, career development to name a few. For the purposes of this narrative, misconduct and performance procedures provide the exemplars. Finally, some summary thoughts are presented about whether the ambition outlined above has been achieved before adding some reflections about opportunities to take this work forward.

\section{Academic Research Context}

In academia, research and writing on conceptualizations of organizational justice are not new. Well over 50 years ago, Homans (1961) explored ideas around distributive justice theory in 
organizations with a particular focus on interpersonal relationships and a reactive approach to the fairness of outcomes, i.e. how workers respond to fair and unfair outcomes. Distributive justice theory was later embellished by Leventhal (1976) as he added a proactive element to the judgement on the fairness of outcomes, i.e. how workers attempt to create fair outcomes. Around the same time, Thibaut and Walker (1975) and Leventhal (1980) were developing the concept of procedural justice with a primary focus on the fairness of process rather than outcomes. Folger and Greenberg (1985) took the conceptualization of procedural justice a stage further with Greenberg (1987, p. 15) commenting about the "proliferation of research and theory about organizational justice". A third conceptualization of organizational justice — interactional justice - emerged from the work of Bies and Moag (1986), see also Cropanzano et al. (2001). The interest in organizational justice and organizational behaviour has continued to grow through the first decade of the 21 st century and which has seen the construction of a fourth justice type, informational justice (Colquitt, 2008).

In more recent years, some commentators have suggested that this singular focus on the effects of specific types of justice may not capture the depth and richness of individuals' justice experiences and that overall justice mediates the relationship between specific justice types and employee attitudes. Moreover, these authors suggest that an overall fairness rubric might broaden the focus of research questions in this area (Ambrose \& Schminke, 2009, p. 491). Colquitt (2012) picks up this theme noting the potential merits of aggregating justice conceptualizations rather than differentiating them. This idea also permeates fairness heuristic theory (Lind, 2001) which suggests that the various dimensions are absorbed by individuals into a "fairness heuristic" which guides future behaviour (Colquitt, 2012). The "simplicity" of fairness theory, when seen to integrate the various elements of organizational justice theory, can offer a way through a complex field whilst aligning with human responses such as "that is not fair" and "I recognize I have been treated fairly" (Komodromos, 2014).

There is also some support for the idea that 'managerial responsibilities' in respect of fair decision making overlap the strands of procedural and interactional justice (Colquitt, 2001). Folger and Bies (1989) categorized these managerial responsibilities as follows: adequate consideration of employees' views, suppressing bias, consistency of decision making, timely feedback, justifying the decision, being truthful and treating employees with respect. This list could easily feature in a 'how to manage people guide' under a generic heading of 'fair' treatment.

Finally in this section, I return to the birth of the term "organization justice" (Greenberg, 1987) to remind the reader that even at this stage, Greenberg was referring to 'just' and 'unjust' events, systems and processes. Ideas that remain at the heart of any discussions about 'just' organizations and 'just' cultures. As this narrative unfolds, an indication of the relationship between fairness, in a just culture, and the opportunities for learning emerge. It is to learning that my attention now turns.

\section{Concepts of Organizational Justice and Fairness}

It is important to share the definitions of organizational justice I will rely on. I have opted for the four dimensional justice types explored in recent research, rather than the three dimensional justice types of distributive, procedural and interactional identified in earlier research (Cropanzano et al., 2001). They are summarized in Figure 1 below. 


\begin{tabular}{|c|c|}
\hline \multicolumn{2}{|c|}{ Organizational Justice } \\
\hline The subjective perception a person has of how fair their organization is. \\
\hline $\begin{array}{c}\text { Distributive Justice } \\
\begin{array}{c}\text { Fairness of the distribution of } \\
\text { organizational resources. }\end{array}\end{array}$ & $\begin{array}{c}\text { Procedural Justice } \\
\text { Fnterpersonal Justice } \\
\text { Inthe decision making processes } \\
\text { within the organization. }\end{array}$ \\
\hline $\begin{array}{c}\text { Fair and respectful treatment of individuals } \\
\text { within the organization. }\end{array}$ & $\begin{array}{c}\text { Informational Justice } \\
\text { Fair amount and timeliness of } \\
\text { shared information. }\end{array}$ \\
\hline
\end{tabular}

Figure 1: Definitions of Organizational Justice (Source: Colquitt, 2001)

The four elements of organizational justice outlined above have been the subject of considerable research in their own right, but there is a growing body of interest in a single conceptualization of fairness, rooted in organizational justice (Ambrose \& Schminke, 2009). It is important to recognize that the rubric of fairness does not stand outside the organizational justice framework and, indeed, has a relationship with the four strands - see Figure 2.

All this said, there is no escaping the subjective, social constructionist nature of 'fairness', and the conclusion that 'fairness' is a multi-faceted conceptualization. Additionally, I suggest that the introduction of organizational "fairness stories" into the debate, drawn from workers' experiences, provide a body of evidence for potential critical discourse analysis or other forms of narrative analysis and an alternative to the emphasis placed on quantitative approaches in research to date.

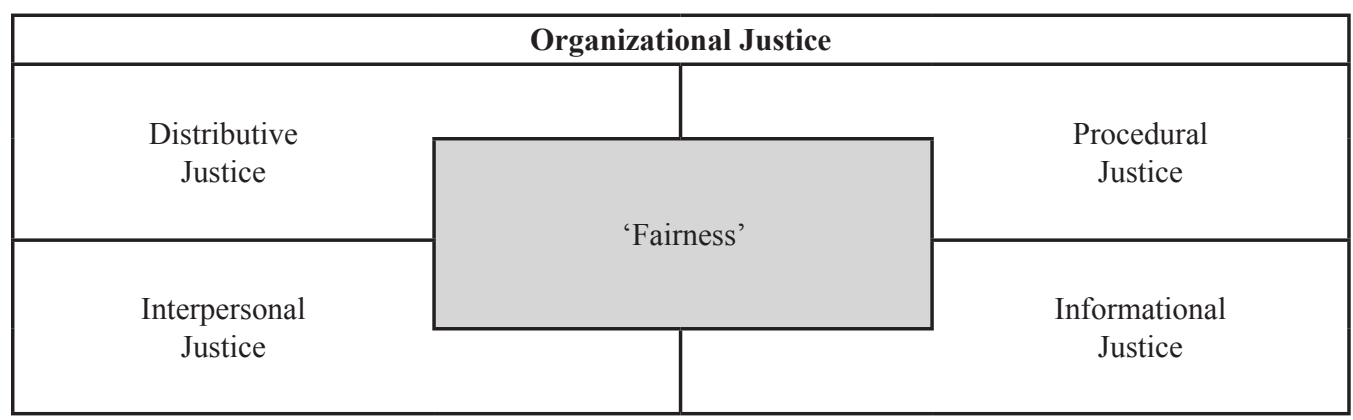

Figure 2: The Relationship of Fairness with the Four Strands

I am drawn to the overall fairness approach in seeking to improve the understanding of fairness in my own organization, particularly as influenced by leadership style and organizational climate and to highlight how the sense of fairness is reported by individuals in their working lives. I also accept that by trying to equate justice with fairness, philosophically speaking at least, I might be on dangerous ground at the more academic level of debate. Nevertheless, it may help to better understand the relative influence of fairness - characterized by the organizational justice paradigm - if employee satisfaction and motivation are expressed in the everyday language of the worker; a sense that this is a 'good place to work' and 'I am treated fairly at work'. Even more pragmatically, an understanding and application of the single concept of 'fairness' may assist the busy manager in reaching conclusions to differentiate learning opportunities from blameworthy events without resorting to the more theoretical ideas expressed in the academic literature. It 
may also go some way towards addressing the issue of the 'use value' of research: that is, to be relevant as well as rigorous (Gold, 2017). This is particularly important in trying to overcome the 'this is too academic and doesn't apply in real life' syndrome.

Gold was, of course, building on Pettigrew's earlier work on the use value of research:

Research without scholarly quality will satisfy no one and will certainly disable our capacity to meet the double hurdle of scholarly quality and relevance (Pettigrew, 2001, p. 61).

For me, there is a third hurdle; application of research in an applied manner across a range of contexts and environments. For the manager, this equates to making their respective industry more successful and their daily tasks easier to undertake.

I attempt to locate the practical application of the principles of organizational justice - as a single fairness concept - in organizational practices by applying an organizational fairness model, to police leadership interventions and to misconduct and performance procedures by way of examples. Attention to the historical academic context and the contemporary search for a 'just culture' based on learning rather than blame, as exemplified by Syed (2015), underpins this research into practice endeavour. It is not, however, an attempt to conduct an empirical study, more a suggestion that the dynamic and inter-relationships exposed here might present fertile ground for such study. My focus is on attempting to simplify a complex landscape in the interests of those trying to operate in the everyday hurly-burly of organizational life. See Figure 3 below.

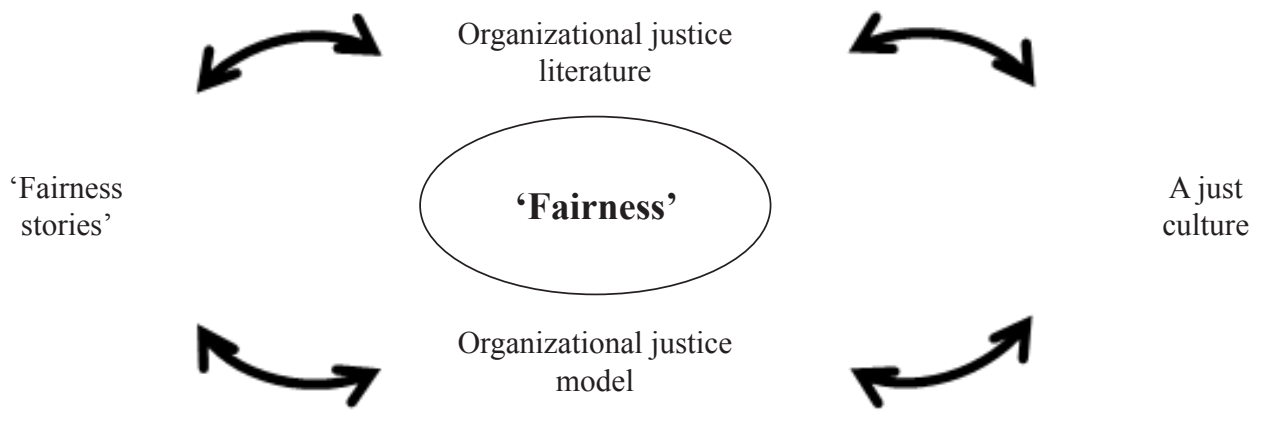

Figure 3: Organizational Landscape

Leaving to one side the academic research journey for a moment, it could be argued that the works of Matthew Syed, particularly Black Box Thinking (2015), have raised the profile and level of interest in individual and organizational learning to new heights. By drawing a stark contrast between the aviation industry and health services, Syed highlights the need to look at failure a-fresh and to consider human actions as part of systematic activities within organizations. The language of near-misses, learning from mistakes and moving away from a culture of blame has become common currency in leadership and management discussions in many organizations. Policing is one arena where such debate has taken hold and is attempting to develop the culture of UK policing by moving from blame to learning and organizational fairness. However, this is not simply a matter of 'flicking a switch' or indeed moving between two simple conceptions.

On occasion, it seems we need a catastrophe to trigger learning in policing. Avoiding catastrophe, let alone responding to it, is hardly a strategic ambition. At the same time, a tendency to seek a 
culprit to blame has fostered a 'climate of fear' in some areas and a reluctance to declare near misses and to learn from mistakes. All of which influences leadership style at all levels. In this climate, it is not easy to promote learning and create a more 'just culture'. To be clear, I am in no way defending serious organizational or individual failings involving serious misconduct or gross negligence. These matters need to be dealt with appropriately through transparent procedures to retain public confidence and the professionalism of the police service.

The way organizations respond to significant failings is, of course, a subject in its own right (Chase et al., 2015) and can have a significant bearing on organizational reputation in the eyes of the public and the workforce. Organizations, and particularly the leaders and spokespersons for those organizations, are quite capable of escalating public antagonism over a blameworthy event to a crisis by what they say and do. However, it is worth pointing out that media stories are not necessarily the same as public opinion. The latter can be more understanding than the media would have us believe and, in general terms, public confidence in policing remains high. On the inside of organizations, and if calls for a scapegoat become louder, employee voice is often subdued and learning opportunities remain hidden. Research around blame is clear that blame can range from very mild to calls for resignation, and everything in between (Hood, 2010). The appropriate response will have a big impact on how staff trust their leadership, the organizational climate that pervades and how Human Resources policies and procedures are regarded and operate in practice.

Under the banner of the "logic of failure" Syed (2015) reminds us that we are quick to blame and quick to disguise our own failings thus limiting our ability to learn and move forward. He also makes the point that we have a tendency to move easily from a complex set of circumstances to a catchy soundbite, although this is not an inevitable consequence. I am struck by the number of occasions we hear the phrase 'don't overcomplicate things' when the more thoughtful recognize the complexity of the issues we are dealing with in organizations like police forces (Rhodes, 2017). We also have a tendency to seek certainty as well as simplicity — a double challenge in a complex and uncertain world. The more we engage with information around us, including research, the more likely we are to promote evidence — based decision making. As Syed (2015, p. 235) puts it "we have to engage with the complexity of the world if we are to learn from it".

As noted earlier, one of the aims of this paper is to explore whether it might be possible to promote cultures of learning and organizational fairness rather than of blame by connecting the organizational research literature with Syed's work and to synthesize the two into a working model of fairness in organizations. My focus is to encourage and promote this culture of organizational learning and to create a climate where staff feel comfortable to report near misses and mistakes. It is also about encouraging managers to spend the time to fully understand events and rationally differentiate between a tendency to seek someone to blame and the truly blameworthy situation. In other words, an aspirational attempt to bridge the divide between organizational theory and organizational practice.

Accordingly, the sections which follow will focus on an attempt to illustrate an organizational model of fairness and to show how such a model might influence aspects of policing practice. As acknowledged earlier, it is problematic to equate justice with fairness at the philosophical level. However, for busy managers, the fairness shorthand may represent a more graspable idea and, perhaps, a pointer to trust in organizational practice. The term a 'just culture', might also seep into the language and practice of our organizations. 


\section{Organizational Justice Model}

Sparrow et al. (2013) make the point that viewing fairness through the lens of organizational justice is only one of a number of options for the Human Resources profession and for line managers, but it is probably the best known and most used. The writers also confirm the complexity of thinking about fairness in an organizational context. As practitioners, though, we need to be in a position of confident, informed decision making and apply a model or approach in 'live' situations. The development of the organizational justice model at Figure 4 below is an attempt to help us do that.

\begin{tabular}{|c|c|c|c|}
\hline $\begin{array}{l}\text { Unintended Action } \\
\text { Unintended Consequences }\end{array}$ & \multicolumn{2}{|c|}{$\begin{array}{c}\text { Intended Action } \\
\text { Unintended Consequences }\end{array}$} & $\begin{array}{c}\text { Intended Action } \\
\text { Intended Consequences }\end{array}$ \\
\hline \multicolumn{4}{|c|}{ Seriousness of consequence } \\
\hline $\begin{array}{l}\text { Lapses in concentration } \\
\text { Minor errors / mistakes }\end{array}$ & $\begin{array}{l}\text { Routine / minor breach } \\
\text { of code of ethics } \\
\text { Breach for } \\
\text { organizational gain }\end{array}$ & $\begin{array}{l}\text { Clear breaches of } \\
\text { ethics } \\
\text { Repeated poor } \\
\text { behaviour } \\
\text { Reckless } \\
\text { Personal gain }\end{array}$ & $\begin{array}{l}\text { Corruption } \\
\text { Operational dishonesty } \\
\text { Deliberate / targeted } \\
\text { discrimination } \\
\text { Overt racism / sexism / } \\
\text { homophobia }\end{array}$ \\
\hline Local managers & Local managers & $\begin{array}{l}\text { Professional } \\
\text { Standards } \\
\text { Department / Anti } \\
\text { Corruption Unit }\end{array}$ & $\begin{array}{l}\text { Professional Standards } \\
\text { Department / Anti } \\
\text { Corruption Unit }\end{array}$ \\
\hline $\begin{array}{r}\text { Unsatisfactory performance } \\
\text { actio }\end{array}$ & and local management & \multicolumn{2}{|c|}{$\begin{array}{l}\text { Misconduct and Gross Misconduct } \\
\text { Proceedings }\end{array}$} \\
\hline Emphasis on learnin & / development & \multicolumn{2}{|c|}{ Discipline and learning } \\
\hline \multicolumn{4}{|c|}{ Accountability } \\
\hline \multicolumn{4}{|c|}{$\begin{array}{l}\text { 1. Clarify which behaviour the alleged actions initially fall within then consider consequence and } \\
\text { accountability. } \\
\text { 2. Would peers of a similar experience, training, and competence have behaved in the same way under } \\
\text { similar conditions? } \\
\text { 3. What would be the public/organizational perception of these actions and the action required? } \\
\text { 4. How have we dealt with similar incidents in the past? }\end{array}$} \\
\hline
\end{tabular}

Figure 4: Organizational Justice Model (Source: Hampshire Constabulary)

In the model, developed by colleagues in Hampshire Constabulary and based on previous work undertaken in the aviation industry, we see an attempt to draw a clear distinction between unintended and intended action and unintended and intended consequences in respect of misconduct and performance procedures. This in itself, requires careful thought and understanding of events before the key decision about whether a blameworthy event has occurred or not is reached.

As part of cultural change programmes in the policing environment, the organizational justice model has featured as a 'mechanism' for looking at misconduct and performance differently, 
with a focus on the opportunities for learning. It has also been used to promote a more supportive leadership style, backed by ethical considerations. In Thames Valley Police, we have run workshops with colleagues at all levels across the Force and incorporated the thinking in many of our learning events and coaching interventions.

An important part of trying to highlight the concepts and benefits of organizational justice has been the involvement of our Staff Associations (the Superintendents' Association and the Police Federation) and our Trade Union (UNISON) from the early stages of our thinking. It is working with them over a wide range of operational and organizational issues that leads to joint outcomes and cohesive working relationships, ultimately allowing us to deliver a better service to the public of the three counties of Berkshire, Buckinghamshire and Oxfordshire. In conjunction with our main collaborative Force — Hampshire Constabulary — we have developed a shared understanding of organizational justice across two organizations working together.

Whilst we are pleased with how the organizational justice model has been received by our staff, concerns remain. The model provides examples of incidents ranging from minor error at one end of the scale through to corruption at the other end of the scale. This does not address sufficiently well how we help managers to take a step back on the receipt of initial information about an incident or issue, to properly understand what has happened and give thoughtful consideration to a proportionate response before jumping to a blameworthy event conclusion and associated formal process. Similarly, the model stops at the point where learning has been shared and/or disciplinary/performance actions taken. It remains silent on how we observe what happens to individual and collective behaviours and the mood and personality of the ongoing organizational climate. The fairness model in the next section seeks to explore these issues and to offer a few thoughts on how we might construct these vitally important pre and post stages of decision making.

\section{Organizational Fairness Model}

The appreciate, sort, learn, observe (ASLO) organizational fairness model at Figure 5 has been developed by the author in an attempt to simplify the decision making process by asking three questions at the outset of our thought processes and to influence our leadership style as we respond:

- Is this a reported near miss?

- Is this an identified mistake or error?

- Is this identified misconduct or negligence?

With a career in the Royal Air Force prior to working in policing, I am very familiar with the strong emphasis on reporting near misses in aviation. As Syed (2015) has eloquently described, near miss reporting needs to be in the bloodstream of the organization to allow learning and changes to technology, machinery or practice to take hold. Even in the Royal Air Force environment, though, I do not recall much evidence of reporting of organizational near misses as opposed to those directly related to aviation. I would argue that the same is true in policing. In the latter, we are good at record keeping, case reviews and post-incident debriefing to review our actions, but often we move to the next incident before we have the opportunity to promote learning. This is particularly so in response policing where officers tend to move onto the next incident as soon 
as they are free to leave the previous one. We are also less good at looking closely at near misses as a matter of routine.

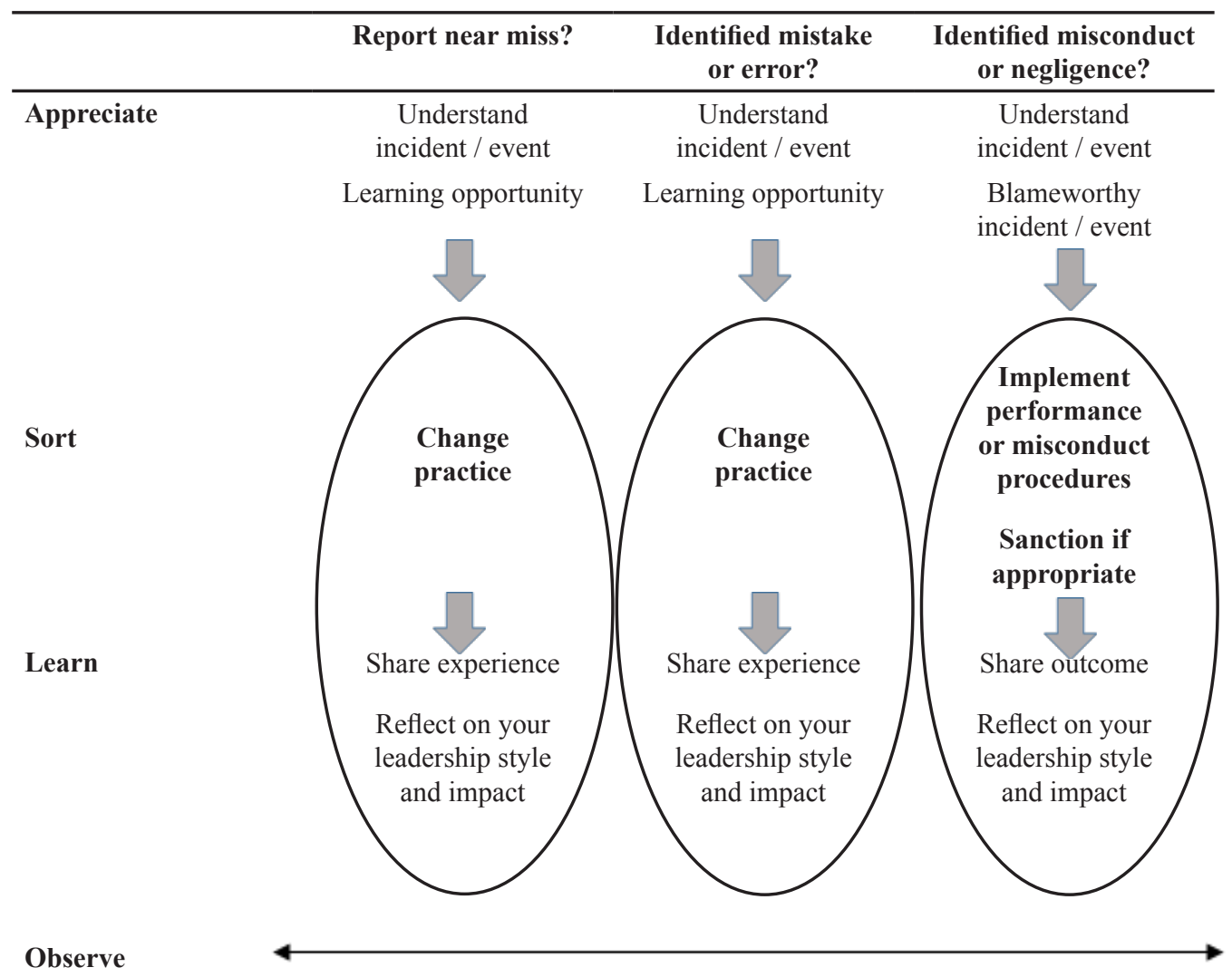

Figure 5: Organizational Fairness Model

When something has happened, the differentiation between identified mistake or error and identified misconduct or negligence becomes crucial, particularly at the pre-managerial response stage and at the early stages of any misconduct or performance procedures. We do have to recognize that, in some cases, we might know at the outset that an incident is blameworthy, but more often than not, we won't. We also have to look at how our processes, police misconduct being a good example, start off and, therefore, set the direction of travel for any formal procedure. If we start with an assessment of likely level of misconduct, we pre-determine the nature and type of investigation. A subsequent finding of no misconduct does little to undo any damage inflicted by the investigative process. The appreciate stage of the ASLO model is, therefore, fundamental if we are to arrive at just outcomes, learning and organizational trust. There will be more on this in the fairness in practice section of this narrative.

The sort and learn elements of the ASLO model are not dissimilar in concept to the organizational justice model in Figure 4 so there will be little further coverage here. Suffice to say that learning and changing practice will be seen by the workforce as fair outcomes in all but the more serious 
cases of misconduct or negligence. Few will regard heavy sanctions for minor infringements as fair. Equally, they will expect serious matters to be dealt with appropriately. This is the balance that leaders and Human Resources professionals seek to achieve.

The importance of the observe element of the ASLO model should not be underestimated. Whilst the corporate memory can be quick to fade in our fast moving worlds, myths and stories linger on, gathering 'truth status' over time, particularly in organizations which generally retains its workforce for many years and has relatively low turnover of staff. Policing falls into this category. Until recently, the police service had a fairly ad hoc approach to understanding their workforce 'climate' with individual forces engaging with a wide range of staff survey providers and, in some cases, not conducting a staff survey at all. These surveys no doubt provided some value to the respective forces, particularly if they tracked changes over time and the leadership of the Force responded to the findings in a positive manner. Too often though, the survey findings - and not just in policing - generate long action plans and become shelf bound quite quickly. As a result, staff lose confidence in their impact and relevance.

Perhaps more concerning around many staff surveys is the lack of academic and theoretical rigour underpinning them and the quality of the analysis of the findings. Free text is often included without appropriate codification and parameters which makes it difficult to analyse and even more difficult to draw generalized conclusions. We should be seeking to link research evidence and underpinning theory, the lived experience, the context of the organization and the resulting practice. Such a combination provides real opportunities for organizational insight and an improved working environment.

In 2014, we attempted to buck this trend in policing by working with Durham University Business School to develop an organizational climate survey based on sound academic and evidencebased principles. From small beginnings, three forces working with Durham University Business School, we have progressed to agreement on a National Survey model for individual forces to subscribe to, endorsed by the National Police Chiefs' Council. We now have 32 participant forces and are building a consistent picture of themes and trends. We have always argued against any form of 'league table' of forces' performance based on the survey and this fundamental principle has been a foundation of the success. For the first time to this writer's knowledge, forces are able to gain an insight into the observe element of the organizational fairness model in the relative comfort of their own data and findings. Moreover, they can hold more sophisticated conversations about areas where potential opportunities for improvement are highlighted.

By way of example, and particularly pertinent to this text, we have been using the climate survey to understand the impact of leadership style on the levels of discomfort felt by staff and the relationship to blame. Insights have been gained through collaborative research into the impact of the different styles of leadership. See Figure 6 below for an example. 


\section{Culture of Learning from Mistakes}

A culture of learning from mistakes refers to the extent to which individuals perceive their organization, and people within the organization, as viewing mistakes or errors as opportunities to learn and develop. Mistakes or errors are considered as a source of feedback for improvement in daily work, and are treated as learning opportunities throughout the organization throughout a series of discussions, analysis, and information-sharing (Gracey et al., 2017).

The Importance of a Culture of Learning from Mistakes in Policing (working paper)

Figure 6: Culture of Learning from Mistakes (Source: Durham University Business School)

The research findings confirm that ethical leadership decreases employee discomfort and authoritarian leadership increases employee discomfort. Moreover, we suggest that an authoritarian leadership style leads to an increased perception of a blame culture and a reluctance to make decisions for fear of being blamed. Conversely, we suggest an ethical leadership style promotes openness and learning and creates a climate for more confident decision making. We plan to test these hypotheses in the climate survey collaboration between Thames Valley Police and Durham University Business School as part of the annual climate survey (Gracey et al., 2017). The research findings also demonstrate that ethical leadership has a positive impact on job satisfaction, emotional energy and engagement, whilst authoritarian leadership has a negative effect on these factors (Graham, 2017). All of which chimes with the commentary provided by the College of Policing in that "a command style of leadership risks disempowerment of people and is the greatest obstacle to achieving a positive culture" (College of Policing, 2015). All that said, we cannot ignore the need for command in certain police contexts, public order situations being a good example. Conscience and compliance have their place!

Organizational fairness also has potential links with ethical guidelines, which are used by most public services to describe, to both members of the organization and the public, what behaviour is to be expected from their employees. Ethical guidelines are likely to be instrumental in determining what incidents might be categorized as problematic or blameworthy, and which are not. One issue facing ethical guidelines is that if they deviate from what members of the organization believe should be expected from them, then it is possible that they could be problematic in terms of perceived organizational fairness. Moreover, the ASLO model requires that an incident is reported and reporting could be affected by whether employees believe their organization to be fair and to possess a code of ethics they think is appropriate and applied.

In terms of policing, Pike and Westmarland (2016) found that, on average, police staff believe the likely punitive outcomes of infringements to the code of ethics are more severe than they should be. This could result in staff not reporting problematic incidents. Ensuring that ethical guidelines reflect beliefs about organizational justice could therefore be an important element in being able to use the ASLO model and in moving away from 'them and us' cultures of blame. There is, of course, a broader canvas for ethics in policing: the ethics of resourcing decisions and prioritization of crimes, for example. Here ethical decision making, based on wisdom and reason, in meeting the public interest is perhaps where we should be putting our effort and dragging ourselves away from ethics resting as the sole preserve of misbehaviours. 


\section{Fairness in Practice}

So far in this text, there have been numerous references to the word 'blame' without explaining what blame means. It is important to do so before venturing deeper into this fairness in practice section. What we should remember, though, is that in more philosophical writings, blame is far from a simple construct and its meaning is widely contested. Lupton and Warren (2016), for example, list four different philosophies of blame:

- Blame viewed as a sanction to shape future behaviour.

- Blame viewed as a judgement on relationship impairment.

- Blame viewed as an emotional reaction to someone having been wronged.

- Blame viewed as part of a social system of power relations.

What we understand by blame and 'no blame' has a significant impact on how we identify blame and, more importantly, how we deal with it. It seems to me that to look for blame or seek to deflect blame, inherently undermines open individual and organizational learning. We also need to understand that individual feelings are driven by perceptions more often than rational outcomes. This is also important when trying to gauge 'blame avoidance' activity and the negative consequences of such activity. Not all blame is negative, of course, as Hood (2010) points out there can be positive consequences from the fear of blame such as reduced rule breaking and allegiance to public service values. This 'positive blame' has relevance in some aspects of policing, as it does in other emergency services.

Even in such symbolic organizational practices as misconduct and performance procedures, 'no blame' can be "characterized by a constructive attitude towards errors and near misses" (Provera et al., 2010, p. 1058). It is not characterized by tolerance of deliberate acts of misconduct, gross negligence or unacceptable behaviour. Moreover, there are some who would question "no blame" in organizations and that what we are really talking about if we wish to promote organization learning, is changing our blaming practices. (Lupton \& Warren, 2016). That is, how we identify and label blameworthy events in the first place and how we address them once identified. As we saw earlier, this formed a key part of my ASLO model. It also involves a shift in emphasis, and indeed management energy, from looking for the person(s) responsible to consider wider systematic change to prevent a recurrence (Shilling \& Klung, 2009). It has been suggested (Weick \& Sutcliffe, 2001) that changing blaming practices might involve:

- 'Safe' error reporting procedures.

- System reflection and learning.

- Processes to identify and implement improvements in a transparent way.

In sum, this plays to the appreciate element of the ASLO model discussed earlier.

Shifting from a blame paradigm in policing involves confronting a deep rooted and pervasive focus on blame as an element of our legalistic processes. From the earliest stages of training and practice, the police officer or police staff member dealing with any form of investigation is encouraged to seek points to prove in criminal cases and thereby attach responsibility to the perpetrators. These traits are reinforced through our misconduct and performance management 
processes which are applied and interpreted in a blame-attaching mode. This can lead to a 'retreat and deny' frame of mind.

We should also recognize the absence of candour in some police misconduct procedures where explanations are only offered as part of legal process. The very opposite of the aviation industry where candour has contributed significantly to improving safety in an inherently dangerous activity. Volunteered explanations in police misconduct procedures offer a number of potential benefits: 'releasing' officers providing satisfactory explanations, satisfying complainants more quickly and avoiding expensive and potentially damaging misconduct hearings. More importantly, learning would ensue at a meaningfully, early stage. In Thames Valley Police, we have eschewed formal misconduct procedures in all but the most serious cases, seeking the learning and marginal gains to nudge the shift to a more just culture. For the individual, this involves admission, contrition and a willingness to share the learning. For the organization, this involves confidence and respect for policy and practice.

\section{Final Reflections}

The most I can claim is to have made a start in understanding organizational justice and fairness and how its application can impact positively on organizational climate. We are beginning to unpick the decision making processes that lead to notions of blame and to see the benefits of decisions leading to learning and changed practice. We have more to do, but the momentum is growing.

I am acutely aware that this article only skims the surface of a complex, and challenging organizational development and cultural body of knowledge. Indeed, in seeking to create some form of bridge between science and practice, I may have muddied the waters still further. To address this, an empirical study of the ASLO model would be timely and, potentially, insightful.

In terms of understanding how leadership styles impact on feelings of fairness, we are already working with Durham Business School on new measures to provide such insight through our staff climate survey. We have high expectations that the new measures will add to our knowledge in this area and allow us to consider more thoughtfully how we turn this evidence base into working practice.

In researching this article, I was struck by the volume of literature on organizational justice and fairness. I was also struck by, but not surprised by, the paucity of research in this area conducted in a qualitative mode. It seems to me that further research through the lens of 'organizational story telling' would add to the use value of the body of research and help the busy manager to better understand the impact of fairness in the workplace.

Two areas of potential further research emerged in this narrative and have been highlighted earlier. First, an empirical study of the ASLO model from evidence-based and theoretical underpinnings through to managerial practice. Second, an interpretation of our climate survey results around the new measures we have developed which seek to help us better understand the impact of leadership styles on feelings of blame in contrast to the impact of leadership styles on fairness and learning. From a personal perspective, I would like to see this further research undertaken using mixed methods and through a critical lens to add further layers of sophistication to the research undertaken hitherto. 


\section{References}

Alvesson, M., Blom, M., \& Sveningsson, S. (2017). Reflexive Leadership: Organising in an Imperfect World. London: Sage.

Ambrose, M. L., \& Schminke, M. (2009). The Role of Overall Justice Judgements in Organizational Justice Research: A Test of Mediation. Journal of Applied Psychology, 94(2), 491-500.

Bies, R. J. \& Moag, J. F. (1986). Interactional Justice: Communication Criteria of Fairness in Lewicki, R.J., Sheppard, B. H., \& Bazerman, M. H. (Eds) Research on Negotiations in Organizations Vol 1 (43-55). Greenwich, C.T: JA1 Press.

Chase, S., Paine, C., Resodilardjo, S., \& Sancino, A. (2015). Police Leaders Dealing with Blame: Some Crisis Leadership Lessons. Open University Centre for Policing Research and Learning.

Cheng, B-S., Chou, L-F., Wu, T-Y., Huang, M-P., \& Farh, J-L. (2004). Paternalistic leadership and subordinate responses: Establishing a leadership model in Chinese organizations. Asian Journal of Social Psychology, 7(1), 89-11.

College of Policing (2015). Leadership Review: Recommendations for Delivering Leadership at all Levels. College of Policing Limited.

Colquitt, J. A. (2001). On the Dimensionality of Organizational Justice: A Construct Validation of a Measure. Journal of Applied Psychology, 86, 386-400. doi 10.1093/oxfordhb/9780199928309.013.0016

Colquitt, J. A. (2008). Two Decades of Organizational Justice: Findings, Controversies and Future Directions in Cooper, C. L., \& Barling, J. (Eds). The Sage Handbook of Organizational Behaviour, Vol 1, Micro Approaches (73-88). Newbury Park, CA: Sage.

Colquitt, J. A. (2012). Organizational Justice. The Oxford Handbook of Organizational Psychology, Vol 1. Oxford: Oxford University Press.

Cropanzano, R., Byrne, Z. S., Bobocel, D. R., \& Rupp, D. R. (2001). Moral Virtues, fairness heuristics, social entities and other denizens of organizational justice. Journal of Vocational Behaviour, 58, 164-209. doi.org/10.1006/jvbe.2001.1791

Folger, R., \& Greenberg, J. (1985). Procedural Justice: An Interpretative Analysis of Personnel Systems in Rowland, K., \& Ferris, G. (Eds) Research in Personnel and Human Resource Management, 3(1), 141-183, Greenwich, CT: JA1 Press.

Folger, R., \& Bies, R. J. (1989). Managerial Responsibilities and Procedural Justice. Employee Responsibilities and Rights Journal, 2(2), 79-89.

Gold, J. (2017). Time to Bridge the Research Practice Divide. International Journal of HRD Practice, Policy and Research, 2(1), 81-82.

Gracey, S., Graham, L., Chase, S., \& Hesketh, I. (2017). The Importance of a Culture of Learning from Mistakes in Policing. Working paper.

Graham, L. (2017). 'Achieving Positive Outcomes through a Collaborative Research Project into Leadership and Service Delivery in Policing' (Invited speaker at the Learning from Evidence: Mission Impossible? Centre for Policing Research Annual Conference, Canterbury, UK, 21-22 June 2017).

Greenberg, J. (1987). A Taxonomy of Organizational Justice Theories. The Academy of Management Review, 12(1), 9-22.

Homans, G. C. (1961). Social Behaviour: its elementary forms. New York: Harcourt, Brace, and World.

Hood, C. (2010). The Blame Game: Spin, Bureaucracy and Self-Preservation in Government. Princeton: Princeton University Press.

Hough, M., Jackson, J., Bradford, B., Myhill, A., \& Quinton, P. (2010). Procedural Justice, Trust and Institutional Legitimacy. Oxford: Oxford University Press.

Kieser, A., \& and Leiner, L. (2011). On the Social Construction of Relevance: A Rejoinder. Journal of Management Studies 48(4), 891-898.

Komodromos, M. (2014). Employees' Perceptions of Trust, Fairness and the Management of Change in Three Private Universities in Cyprus. Journal of Human Resources Management and Labor Studies, 2 (2), 35-54.

Leventhal, G. S. (1976). Fairness in Social Relationships. Thibaut, J. W., Spence, J. T., \& Carson, R. C. (Eds). Contemporary Topics in Social Psychology, 211-239. Morristown. NJ: General Learning Press. 
Leventhal, G. S. (1980). What Should be done with Equity Theory? Gergen, K. J., Greenberg, M. S., \& Willis R. H. (Eds) Social Exchange: Advances in Theory and Research, 27-55: New York: Plenum.

Lind, E. A. (2001). Fairness Heuristic Theory: Justice Judgements as Pivotal Cognitions in Organizational Relations. Greenberg, J., \& Cropanzano, R. (Eds) Advances in Organizational Justice, 56-88, Standford, CA: Stanford University Press.

Loi, R., Yang, J., \& Diefendorff, J. M. (2009). Four-Factor Justice and Daily Job Satisfaction: A MultiLevel Investigation. Journal of Applied Psychology, 94(3), 770-781. doi: 10.1037/a0015714

Lupton, B., \& Warren, R. (2016). Managing Without Blame? Insights from the Philosophy of Blame. Journal of Business Ethics. doi.org/10.1007/s10551-016-3276-6

Pettigrew, A. M. (2001). Management Research After Modernism. British Journal of Management, 12(1), 61-70. doi:10.1111/1467-8551.12.s1.8

Pike, G., \& Westmarland, L. (2016). Comparing practitioner and public perceptions of police integrity. Paper presented at the European Association of Psychology and Law, Toulouse, 2016.

Provera, B., Montefusco, A., \& Canato, A. (2010). A 'no blame' Approach to Organizational Learning. British Journal of Management, 21(4), 1057-1074. doi:10.1111/j.1467-8551.2008.00599.x

Rhodes, A. (2017). Are you a Chicken or a Pig? Reflections on why (it may possibly be) Leaders Ignore the Evidence when it comes to change ... Open University Centre for Policing Research.

Schneider, B., Ehrhart, M. G., \& Macey, W. H. (2013). Organizational Climate and Culture. Annual Review of Psychology, 64, 361-388. doi.org/10.1146/annurev-psych-113011-143809

Shilling, J., \& Klug, A. (2009). Barriers to Organizational Learning: An Integration of Theory and Research. International Journal of Management Reviews, 11(3), 337-360.

Sparrow, P., Wong, W., Otaye, L., \& Bevan, S. (2013). The changing contours of fairness: Can we match individual an organisational perspectives? London: CIPD Publishing.

Syed, M. (2015). Black Box Thinking. London: John Murray.

Thibaut, J., \& Walker, L. (1975). Procedural Justice: A Psychological Analysis. Hillsdale, N.J.: Lawrence Erlbaum Associates.

Weick, K. E., \& Sutcliffe, K. (2001). Managing the Unexpected. Assuming High Performance in an Age of Complexity. Hoboken, NJ: Wiley.

\section{Acknowledgements}

Dr. Les Graham and Professors Jean Hartley and Graham Pike for their invaluable advice and input. A number of colleagues at Thames Valley Police for their professional guidance and Chantelle Young for her patience and skill in putting this article together.

\section{The Author}

Previously a Royal Air Force Group Captain, Steven is now the Director of People at Thames Valley Police and President of the Chartered Institute of Personnel and Development Police Forum. Steven's professional interests include reflexive leadership, organisational development and evidence based practice.

Steven was awarded a Doctorate of Business Administration from Sheffield Hallam University in 2007. Steven is a Visiting Fellow at Sheffield Business School and at the Open University. He is the joint chair of a consortium working with Durham University Business School on workforce climate and staff engagement.

Steven was appointed an Officer of the Order of the British Empire in the New Year 2017 Honours List for services to policing. 
